\title{
ENCUENTROS ENTRE LA UNIVOCIDAD Y LA DIFERENCIA. SPINOZA EN EL JOVEN DELEUZE
}

\author{
Myriam Hernández Domínguez* \\ Universidad de La Laguna \\ myriamhernandez.rpf.ull@gmail.com
}

\section{RESUMEN}

Gilles Deleuze es uno de los pensadores más destacados de las últimas décadas del siglo xx. Sin embargo, algunas de sus primeras producciones filosóficas parecen haber caído en el olvido. El objetivo de este trabajo es retomar una de ellas, a saber, Spinoza y el problema de la expresión, con el fin, no solo de mostrar la interpretación que Deleuze desarrolla en esta de la filosofía de Baruj Spinoza, sino de ponerla en relación con la obra, quizás, más reconocida de su juventud filosófica, Diferencia y repetición. Lo que pretendo es vincular, sonsacar, qué hay de las monografías que Deleuze dedica a Spinoza en Diferencia y repetición, el texto más destacado de su producción pre-Guattari.

Palabras Clave: Deleuze, Spinoza, expresión, diferencia, repetición, univocidad.

\section{ENCOUNTERS BETWEEN THE UNIVOCITY AND THE DIFFERENCE. SPINOZA IN THE YOUNG DELEUZE}

Abstract

Gilles Deleuze was one of the most influential philosophers of the second half of the twentieth century. Nevertheless, some of his first philosophical production seems to have fallen into oblivion. Thus, the aim of this article is to recover one of them, namely, Spinoza and the problem of expression, and try to put it in relation to his youth seminal text, Difference and Repetition.

Keywords: Deleuze, Spinoza, expression, difference, repetition, univocity.

DOI: http://doi.org/10.25145/j.laguna.2018.43.002 
Bosquejar entre las raíces, los encuentros y desencuentros del materialismo resulta un ejercicio necesario para acercarse a las nuevas teorías y problemáticas filosóficas sobre posthumanismo o nuevos materialismos que están protagonizando una parte destacable de la producción intelectual de nuestro siglo. Ese es el propósito de este trabajo, recuperar los planteamientos ontológicos de dos destacados referentes para estas nuevas teorías: Baruj Spinoza y Gilles Deleuze. En concreto, la pregunta que guía estas páginas es la siguiente: ¿qué hay de la primera monografía que dedica Gilles Deleuze a Spinoza en Diferencia y repetición?

Deleuze es uno de los pensadores más destacados del siglo xx, que, junto con Felix Guattari, escribe obras de notable repercusión como El Anti-Edipo (1972) o Mil Mesetas $(1980)^{1}$. Sin embargo, mi intención es rescatar las primeras obras del filósofo francés, concretamente Spinoza y el problema de la expresión (1968), para vincularla con el que será el texto más reconocido de su juventud filosófica, Diferencia y repetición (1968). Deleuze es uno de los grandes pensadores de la diferencia. Su recorrido por este concepto, aunque parezca partir de Diferencia y repetición y prolongarse a lo largo de toda su producción filosófica, se va constituyendo en sus primeras obras. Deleuze trata de alejarse de los dualismos cartesianos, de las tríadas dialécticas, de las reducciones, para promover la diferencia, disidencias y alteridades irreductibles. Deleuze se dirigió hacia filósofos situados al margen de la historia de la filosofía: Lucrecio, Spinoza, Hume, Bergson o Leibniz, en los que descubrió un potencial materialista, antimecanicista, univocista y vitalista. Spinoza es, para el pensador francés, el gran ontólogo, pensador de la univocidad, la inmanencia y las multiplicidades. En mi entusiasmo por estos planteamientos protagonizados por la diferencia y la génesis de la subjetividad pretendo abordar la relevancia de Spinoza en las obras más tempranas de Deleuze.

Spinoza es, para Deleuze, el filósofo de los filósofos ${ }^{2}$. Su admiración por Spinoza no se debe solo a su aparente «latín tranquilo» y su manera de dirigirse a los no filósofos ${ }^{3}$, sino por el conjunto de su pensamiento, al que toma como referencia

* Esta investigación ha sido realizada con el apoyo de la Ayuda para Contratos Predoctorales FPU 2017 (Formación del Profesorado Universitario) del MECD. Este trabajo forma parte de proyecto I+D «Justicia, Ciudadanía y Vulnerabilidad. Narrativas desde la precariedad y enfoques interseccionales» (FFI2015-63895-C2-1-R), Ministerio de Economía y Competitividad de España. Este artículo forma parte de un trabajo realizado en el marco del Grupo de Investigación Repensar la Filosofía de la Universidad de La Laguna.

${ }^{1}$ Para una explicación cuidada y detallada del proceso de producción de estas obras y el encuentro entre ambos autores, véase Dosse, F. Gilles Deleuze y Felix Guattari. Biografía cruzada, FCE, Buenos Aires, 2009.

2 Deleuze, G. Conversaciones 1972-1990, Pre-Textos, Valencia, 1996, p. 234.

3 «En esto reside el estilo de Spinoza, bajo su latín tranquilo en apariencia. La paradoja de Spinoza consiste en que siendo el filósofo más puro es, al mismo tiempo, el que más se dirige a 
en gran parte de su producción filosófica ${ }^{4}$, si bien en este trabajo atiendo a Spinoza y el problema de la expresión, que, junto a Diferencia y repetición, conforman su tesis doctoral. Años más tarde, en 1970, recuperará la filosofía de Spinoza, dedicándole otro monográfico titulado Spinoza, filosofía práctica. En este apartado me detengo a exponer la lectura que hace Deleuze de los conceptos de expresión, univocidad e inmanencia, claves tanto para la propia filosofía spinozista como para la concepción de la diferencia y la repetición que desarrolla Deleuze.

Deleuze hace presentar a la expresión como una tríada: substancia, atributos y esencia ${ }^{5}$. La substancia se expresa, los atributos son las expresiones y la esencia es expresada ${ }^{6}$. La substancia se distingue de los atributos en tanto que cada atributo expresa una esencia. La esencia y el atributo se distinguen, por su parte, en que cada esencia es expresada como esencia de la substancia y no del atributo. La originalidad del concepto de expresión, según Deleuze, reside en lo expuesto, la esencia no existe fuera del atributo que la expresa, pero en tanto que es esencia no se refiere sino a la substancia. Una esencia es expresada por cada atributo, pero como esencia de la substancia misma ${ }^{7}$. Esto no implica que los atributos existan por sí o que su existencia sea deducida de su esencia, el atributo es concebido por sí y en sí. Deleuze sostiene que sumergirse en las consideraciones spinozistas sobre el atributo implica bosquejar el Tratado breve, del que nos advierte que sus fórmulas sumamente complejas permiten al lector elegir entre distintas hipótesis: suponer fechas distintas en la redacción, imperfección en los manuscritos o aludir al estado aún vacilante del pensamiento de Spinoza. Sin embargo, para Deleuze no parece ser así; los fragmentos del Tratado breve no solo son superados por la Ética, sino transformados. $\mathrm{Y}$ esta transformación, a juicio del pensador francés, se produce por la utilización más sistemática de la idea de expresión. Ambos textos, insiste Deleuze, señalan lo siguiente: que a la esencia de los atributos pertenece la existencia y, por tanto, no existe esencia o ser alguno fuera de ellos, que concebimos los atributos solo en su esencia y no en su existencia, no se conciben como subsistentes por sí mismos, que los atributos existen formalmente y en acto ${ }^{8}$.

los no filósofos y quien más interesamente solicita una comprensión no filosófica», Deleuze, G. Ibidem, p. 235.

${ }^{4}$ Deleuze confiesa que es sobre Spinoza «sobre quien más he trabajado seriamente» (la traducción es mía), Deleuze, G. y Parnet, C. Dialogues, Flammarion, París, 1996, p. 22.

5 «La distinción formal es tan real como la de contenido, pero no introduce ningún tipo de multiplicidad numérica en la substancia; en esencia, la substancia es una, pero esta unidad esencial se puede expresar en sí misma de un número infinito de maneras, desde un número infinito de puntos de vista. Estos puntos de vista son los atributos, cada uno de los cuales expresa completamente la esencia de la substancia, pero desde una determinada perspectiva. Así pues, la primera tríada de términos que comporta la expresión de la substancia en sí misma, es la que distingue entre la substancia, la esencia y el atributo», Cerezo, A. «Deleuze, lector de Spinoza. Del problema de la expresión a la filosofía práctica», Convivium, 24, 2011, pp. 163-180.

${ }^{6}$ Deleuze, G. Spinoza y el problema de la expresión, Muchnik, Barcelona, 1975, p. 24.

7 Ibidem.

8 Ibidem, pp. 35-36. 
Atendiendo a la primera consideración, es decir, que la esencia en cuanto tal no existe fuera de los atributos que la constituyen, es posible concluir que «la esencia se distingue en los atributos donde existe»" Los atributos son la existencia de una esencia eterna e infinita, de una esencia particular, por ello el existir es propio a la esencia de los atributos en tanto que existir en los atributos. Deleuze explica esta relación de manera esclarecedora en su clase del 25 de noviembre de 1980 en Vincennes:

Es precisamente eso lo que Spinoza define como la substancia ${ }^{10}$ que posee todos los atributos iguales, que posee toda cosa como modos. Los modos de la substancia son el ente, la substancia absolutamente infinita es el ser en tanto que ser, los atributos, iguales unos a otros, son la esencia del ser. Y tienen ahí esa especie de plano sobre el cual todo es aplastado y donde todo se inscribe ${ }^{11}$.

Asumiendo, entonces, que la substancia infinita es el ser, la esencia del ser son los atributos y los modos de la substancia el ente, podemos avanzar en la pregunta que se hace Deleuze respecto a las citadas consideraciones: ¿cómo puede decirse que los atributos expresan, no solo una cierta esencia, sino la esencia de la substancia? ${ }^{? 2}$. La esencia se expresa como esencia de las substancia y no del atributo; por tanto, aunque sean distintas en los atributos en que existen, todas se funden en la substancia de la que son esencia. En palabras de Deleuze, todas las esencias existentes son expresadas por los atributos en los que existen, pero como esencia de otra cosa, "de una sola y misma cosa para todos los atributos, la substancia, el correlativo de la esencia, y no el atributo en que la esencia existía solo como esencia ${ }^{13}$. Los atributos, entonces, expresan la esencia de la substancia; recordemos que la substancia se expresa, los atributos son expresiones y la esencia es expresada. Los atributos son, en Spinoza, según Deleuze, «atribuidores» y no «atribuidos». ¿Qué es lo que atribuye y a qué? La esencia que expresa a la substancia. Las esencias atribuidas se confunden en la substancia de la que son esencia. Plantear el atributo como "atribuidor» permite concebirlo como atribuyendo su esencia a algo idéntico a todos los atributos, a saber, la substancia. Es decir, estos relacionan su esencia a un Dios inmanente y este nos

${ }^{9}$ Ibidem, p. 36.

${ }^{10}$ Spinoza inicia su ontología planteando el concepto de substancia. No es una categoría especulativa sobre lo que puede ser sino una categoría material sobre lo que es infinitamente. En palabras de Spinoza: «Por substancia entiendo aquello que es en sí y se concibe por sí, es decir, aquello cuyo concepto no necesita el concepto de otra cosa, por el que deba ser formulado", $E 1$, Definiciones. Este concepto de substancia sobrepasa el dualismo cartesiano (res cogitans y res extensa), puesto que lo que Spinoza observa no es más que una única substancia que podríamos traducir como «cosmos infinito» o "naturaleza infinita». Hablamos, por tanto, de esa naturaleza infinita que nos rodea y de la que formamos parte, a la que también podemos llamar Dios, en el sentido deus sive natura: "Por Dios entiendo el ser absolutamente infinito, es decir, la substancia que consta de infinitos atributos, cada uno de los cuales expresa una esencia eterna e infinita», $E 1$, Definiciones.

${ }^{11}$ Deleuze, G. En medio de Spinoza, Cactus edición digital, Buenos Aires, 2011, p. 15.

12 Ibidem, p. 36.

13 Ibidem. 
hace comprender que el hecho de que Deleuze afirme que «los atributos en Spinoza son verdaderos verbos ${ }^{14}$ es así porque poseen un valor expresivo, no son atribuidos a substancias variables, sino que atribuyen y expresan una esencia infinita a una substancia única ${ }^{15}$. Tal y como explica Cerrato: «Los atributos implican y explican la cualidad infinita de la sustancia, su esencia infinita ${ }^{16}$. Esto es, cada atributo expresa una esencia infinita, una cualidad ilimitada, cualidades substanciales en tanto que cada una de ellas califica una misma substancia.

Los atributos, por tanto, constituyen la esencia de la substancia, pero no la esencia de los modos o criaturas. Deleuze enfatiza que las criaturas implican los atributos en su esencia y existencia, es decir, "son formas comunes» ${ }^{17}$. La esencia, entonces, no solo se entiende como como aquello sin lo que la cosa no puede ser concebida, sino que, además, sin la cosa, ni puede ser ni puede ser concebida. Escribe Spinoza al respecto en su Ética:

En efecto, el ser de la substancia no pertenece a la esencia del hombre. Es, pues, algo que está en Dios y que sin Dios no puede ser ni ser concebido, o sea, una afección o modo, que expresa la naturaleza de Dios de cierta y determinada manera ${ }^{18}$.

Los atributos no son esencia del modo, del ser humano, por ejemplo. Los atributos son formas comunes a Dios - del que constituyen su esencia- y a los modos o criaturas - los implican esencialmente-. Aunque las criaturas y Dios difieran como esencia de la existencia, las mismas formas se afirman de Dios y de las criaturas. Aunque Dios y las criaturas difieran por esencia y existencia, no implica que nada tengan en común. Todo lo contrario, la originalidad de Spinoza se manifiesta en defender que los mismos atributos que se afirman de Dios dan lugar a modos que los implican bajo la misma forma que aquella que conviene a Dios ${ }^{19}$. Lo que trata de poner de manifiesto Deleuze es que Spinoza opera con nociones comunes, y que toda su reconocida teoría sobre las nociones comunes parte de ese estatus del atributo. Los atributos son formas de ser unívocas, no cambian de naturaleza al cambiar de sujeto: cuando se las predica del ser infinito y de los seres finitos, de la substancia y de los modos, de Dios y de las criaturas ${ }^{20}$. Los atributos son verbos que expresan cualidades ilimitadas que están englobadas en los límites del finito; son, además, expresiones unívocas de Dios. Estas constituyen la naturaleza de Dios como natura

14 Ibidem.

15 Tristano Bernardis lo resume de manera clara: «El atributo de Spinoza, para Deleuze, es una forma dinámica y activa, es expresión. La esencia de la substancia no reside fuera de los atributos que la expresan porque, al mismo tiempo, atribuye su esencia a una sustancia única para todos los atributos. El atributo no es un atribuido sino un atribuidor» (la traducción es mía), Bernardis, T. «Deleuze, Spinoza, l’Espressione», Esercizi Filosofici, 12, 2017, pp. 24-39.

${ }^{16}$ Cerrato, F. «Espressione e vita: lo Spinoza di Gilles Deleuze», Dianoia, 12, pp. 301-330.

17 Deleuze, G. Op. cit., p. 41.

${ }_{18} E$, II, 10, demostración del corolario.

19 Deleuze, G. Op. cit.

${ }^{20}$ Ibidem, p. 42. 
naturans y se engloban en la natura naturata ${ }^{21}$. Por esto dirá Deleuze que la filosofía de Spinoza permanece en parte ininteligible si no se ve en ella una lucha constante contra las tres nociones de equivocidad, eminencia y analogía.

La naturaleza de Dios es expresiva por sí misma como natura naturans. Cada atributo expresa una esencia formal que, en conjunto, son expresadas como esencia absoluta de una substancia de la que se deriva la existencia. Esta última es expresada por los atributos. Estos momentos, según Deleuze, son «los verdaderos momentos de la substancia $»^{22}$, es decir, la expresión es, en Dios, su propia vida, no pudiéndose decir que Dios produce el mundo o la natura naturata para expresarse; Dios se expresa en sí mismo, en los atributos que lo constituyen. De este modo, si Dios se expresa en sí mismo, el universo es una expresión de segundo grado, esto es, la substancia se expresa ya en los atributos que constituyen la natura naturans, pero los atributos se expresan, a su vez, en los modos, que constituyen la natura naturata ${ }^{23}$. Esto implica, tal como explica José Luis Pardo, que en todo individuo está impreso, implicado, todo el ser en cierto nivel intensivo:

Como en un grado de blanco están implicados todos los (infinitos) grados de blanco: lo finito es un pliegue de lo infinito, la esencia intensiva de cada individuo es eterna en la medida en que forma parte de la inmensidad de la substancia ${ }^{24}$.

Realizar esa esencia intensiva que es el individuo implica desplegar la infinitud, explicar lo que comprende, expresar lo que es. De esta manera la expresión es un momento clave en la elaboración de la individualidad, pues en tanto se expresa, el individuo produce afecciones, se convierte en una síntesis activa.

${ }^{21}$ Spinoza establece una distinción clave su Ética: natura naturans y natura naturata. Por natura naturans debemos entender aquello que es en sí y se concibe por sí ( $E, \mathrm{I}, 29$, escolio). Por natura naturata se entienden los modos de los atributos de Dios. En el esquema con el que parte Spinoza su ontología, la natura naturans es la substancia infinita, que dispone de atributos infinitos. La natura naturata se referirá a los modos de los infinitos atributos de la substancia. Esto significa que la substancia no es infinita por ser infinita sino porque tiene infinitos atributos. Es decir, la substancia infinita tiene sus cualidades propias, que podemos llamar atributos. Como la substancia es infinita habrá infinitos atributos. Consecuencia de esa natura naturans, existe una natura naturata poblada de modos de estar de esos infinitos atributos. Existe un modo vegetal, este es un modo de estar de una extensión; algo físico que está en el universo, y un modo humano que, no es solo modo físico extenso, sino que además está capacitado para el pensamiento.

${ }^{22}$ Deleuze, G. Ibidem, p. 93.

${ }^{23}$ Ibidem.

${ }^{24}$ Pardo, J. Deleuze: Violentar el pensamiento, Pedagógicas, Madrid, 1990, p. 49. 
Al inicio de la segunda parte de la Ética, Spinoza explica:

Hemos mostrado que Dios actúa con la misma necesidad con que se entiende a sí mismo, esto es, que, así como de la necesidad de la naturaleza divina se sigue que Dios se entiende a sí mismo, con la misma necesidad se sigue también que Dios hace infinitas cosas en infinitos modos [...]. Hemos mostrado que la potencia de Dios no es otra cosa que la esencia actuante de Dios; y, por tanto, tan imposible nos es concebir que Dios no actúa como que Dios no existe ${ }^{25}$.

De esta comprensión de Dios, Deleuze distinguirá dos argumentos. El primero, que Dios actúa o produce como comprende ${ }^{26}$, es decir, que, comprendiéndose necesariamente, actúa necesariamente. El segundo, que Dios produce como existe, existiendo necesariamente, produce necesariamente. Respecto al primer argumento, Deleuze insiste en que Dios no concibe posibilidades en su entendimiento. Esto es, el entendimiento infinito no es el lugar de los posibles, sino más bien la idea que tiene Dios de su propia esencia, de su propia naturaleza. Comprender implica, por tanto, no la concepción de algo como posible, sino la deducción de propiedades a partir de lo que se aprehende como necesario, es decir: «Dios se comprende él mismo; una infinidad de propiedades que caen necesariamente bajo el entendimiento de Dios, se originan ${ }^{27}$. De modo que Dios comprende su propia esencia, pero, inevitablemente, produce una infinidad de cosas: los modos se asimilan a propiedades lógicas necesarias que parten de la esencia de Dios tal como es comprendida ${ }^{28}$.

Para Deleuze, Spinoza plantea que Dios se comprende como axioma, aunque es demasiado original como para fundarse sobre un simple axioma. Esa concepción spinozista se remite a Aristóteles. Que Dios se piensa a él mismo quiere decir que es él mismo el objeto de pensamiento, es el objeto de la ciencia. Señala Deleuze que muchos comentadores expertos en la filosofía aristotélica han encontrado argumentos suficientes para sostener que el Dios de Aristóteles, pensándose a sí mismo, piensa también las demás cosas, se produce una identificación del cognoscente, el conocimiento y lo conocido ${ }^{29}$. Sin embargo, esta teoría spinozista de la idea de Dios no es reductible ni a una tradición ni a un axioma; el hecho de que Dios se comprenda

${ }^{25} E$, II, 3, escolio.

26 Deleuze, G. Op. cit., p. 94.

27 Ibidem.

${ }^{28}$ Retomo un ejemplo de Spinoza para ilustrar este planteamiento: «Antes de seguir adelante, debemos recordar aquí lo que hemos demostrado antes, a saber, que todo lo que puede ser percibido por el entendimiento infinito como constitutivo de la esencia de la substancia, todo eso pertenece sólo a la única substancia; y que, por consiguiente, la substancia pensante y la sustancia extensa es una y la misma substancia, que es comprendida ora bajo este ora bajo aquel atributo [...]. Por ejemplo, un círculo que existe en la naturaleza y la idea de ese círculo existente, que también existe en Dios, es una y la misma cosa, que se explica por diversos atributos», $E$, II, 7, escolio.

${ }^{29}$ Deleuze, G. Op. cit., p. 95 y ss. 
él mismo se desprende de la necesidad de la naturaleza divina. Deleuze pone de manifiesto la importancia de la expresión en esta consideración, a saber, que Dios no se expresa sin comprenderse en tanto se expresa y que, por tanto, Dios no se expresa en sus atributos sin comprenderse. Por esto, concluye, «a partir de la definición de atributo, Spinoza se refería a un entendimiento capaz de percibir ${ }^{30}$, entendiendo "percibir» como la capacidad del entendimiento de acoger solo aquello que existe en la naturaleza. De modo que del hecho de que Dios tenga infinitos atributos que expresan, cada uno de ellos, una esencia infinita, es posible deducir que Dios se comprende y produce todas las cosas que caen bajo un entendimiento infinito:

Y, como la naturaleza divina tiene atributos infinitos, en sentido absoluto (por 1/dG), cada uno de los cuales expresa una esencia infinita en su género, de su necesidad deben seguirse necesariamente infinitas cosas en infinitos modos (esto es, todas cuantas pueden caer bajo el entendimiento infinito ${ }^{31}$.

Regresemos al segundo argumento: Dios produce como existe. Dios produce necesariamente una infinidad de cosas que le afectan. Los modos ya no son entendidos como propiedades lógicas sino como afecciones, de manera que cuanta más potencia (potentia) tenga una cosa, más puede ser afectada. Dios tiene una potencia absolutamente infinita de existir ${ }^{32} y$, por tanto, puede ser afectado de infinitas maneras (potestas) ${ }^{33}$. Deleuze insistirá en que la idea de que Dios produzca necesariamente nos dice, al mismo tiempo, cómo produce, trataré de sintetizarlo. Afirmábamos que Dios actúa como se comprende y como existe, comprendiéndose como substancia compuesta de infinidad de atributos, y existe como substancia, compuesto de una infinidad de atributos. Por tanto, en los atributos se expresa la esencia y la existencia de Dios. De modo que las cosas producidas siempre se dan en los atributos, nunca fuera: "[Dios] produce una infinidad de cosas, pero en una infinidad de modos ${ }^{34}$. Si bien los atributos son unívocos, lo son en tanto que condiciones bajo la que Dios existe y actúa. En palabras de Deleuze, se dicen, bajo la misma forma, de las criaturas y del creador, de los productos y del productor, constituyendo formalmente la esencia del uno, conteniendo formalmente la esencia de los otros ${ }^{35}$. Nos encontramos, entonces, ante una doble univocidad ${ }^{36}$. En palabras de Francisco Martínez:

${ }^{30}$ Ibidem.

${ }^{31} E$, I, 16, demostración.

32 Deleuze, G. Op. cit.

33 «... las potencias deben distinguirse de los atributos: Dios tiene dos potencias absolutamente infinitas, existir y pensar, mientras que posee infinitos atributos» (la traducción es mía), Bernardis, T. Op. cit., p. 28.

${ }^{34}$ Deleuze, G. Op. cit.

35 Ibidem.

36 Ibidem, p. 97. 
En primer lugar, la univocidad de los atributos que constituyen la esencia de la substancia, además hay una univocidad de la causa, ya que Dios es causa sui, y además causa inmanente, no transitiva de todas las cosas [...]. Hay, por tanto, en Spinoza la univocidad del ser, expresada en la forma común; una univocidad del producir que se manifiesta en Dios concebido como causa común de todas las cosas ${ }^{37}$.

Los atributos son, entonces, verbos, más que adjetivos, pues cada uno es una expresión dotada de sentido, designando la substancia como una sola y misma $\operatorname{cosa}^{38}$. Este juego entre el sentido expresado y el objeto que se expresa pone en marcha cierto movimiento de la expresión en tanto que es necesario, no solo que la substancia se exprese en los atributos y que estos expresen una substancia, sino, además, que los atributos se expresen, a su vez, en modos que los designan. En última instancia, habíamos señalado que Dios produce, al tiempo que sus atributos se expresan, esto es, que Dios se encuentra designado por las cosas y los atributos designan a Dios. El orden en el que Dios produce es el orden de la expresión de los atributos. De manera que, en primer lugar, los atributos se expresan en su naturaleza: «Un modo infinito inmediato es pues la primera expresión del atributo ${ }^{39}$. En segundo lugar, el atributo se expresa en un modo infinito mediato. Por último, el atributo se expresa de una infinidad de maneras que constituyen los modos existentes finitos ${ }^{40}$. Estos modos infinitos poseen en cada atributo leyes según las cuales los modos finitos correspondientes son ordenados. Deleuze habla de una «identidad de orden $»^{41}$ en tanto que los atributos se expresan en un mismo orden y los modos infinitos deben tener el mismo orden en los distintos atributos. Esta identidad de orden define una correspondencia de modos, esto es, que a cualquier modo de un atributo le corresponde un modo de cada uno de los otros atributos.

Esto conducirá, según Deleuze, a la primera forma del denominado «paralelismo» de Spinoza: «Hay una identidad de orden o correspondencia entre modos de atributos diferentes» ${ }^{42}$. Es posible denominar "paralelas» dos cosas que se encuentran en relación constante y no hay causalidad entre ambas. Sin embargo, esta identidad

${ }^{37}$ Martínez habla de una triple univocidad, en sus palabras, de "tres niveles». Aunque en este punto solo nos interesen los dos primeros, muestro el tercero de ellos: «... por último, se da en Spinoza una univocidad de la noción común adecuada que es la misma en la parte y en el todo: aquello es que común a todas las cosas y que está igualmente en la parte y en todo», MARTínEz, F. «Ontología y diferencia: la filosofía de Gilles Deleuze», Eikasia, 23, pp. 33-330. Se trata de una univocidad del conocer que se expresa a partir de la noción común como idea perteneciente al segundo género de conocimiento spinozista. Indica Martínez que es esta insistencia en la univocidad lo que distingue, a juicio de Deleuze, la teoría de la expresión univocista de Spinoza de la teoría de la expresión de Leibniz, basada en la equivocidad.

${ }^{38}$ Martínez, F. Ibidem, p. 234.

39 Deleuze, G. Op. cit., p. 100.

40 «Todo lo que existe necesariamente y es infinito, debió seguirse necesariamente o de la naturaleza absoluta de algún atributo de Dios o de algún atributo modificado por una modificación que existe necesariamente y es infinita», $E, \mathrm{I}, 23$, proposición.

${ }^{41}$ Deleuze, G. Op. cit.

${ }^{42}$ Ibidem, p. 102. 
de orden o correspondencia no es suficiente, Spinoza no se contenta con ello para explicar el vínculo que entrelaza a los modos con los atributos diferentes. Por ello, Deleuze va a resaltar una segunda y una tercera fórmulas del paralelismo: por un lado, la «identidad de conexión o igualdad de principio», por otro, «la identidad de ser o unidad ontológica». La identidad de conexión no se refiere a una simple autonomía de series o cosas correspondientes, sino a una igualdad de principios entre ellas: «Las paralelas en un sentido preciso, exigen una igualdad de principio entre dos series de puntos correspondientes [...]. Los puntos de una curva no se concatenan con los de una recta ${ }^{43}$. Esto explica que los modos de los atributos diferentes no solo poseen el mismo orden (primera fórmula) sino que, además, la misma conexión, es decir, los principios de los que dependen son iguales. Tal como explica Tristano Bernardis, «atributos y modos diversos son partes iguales de un todo y, de este modo, no cabe eminencia de unos sobre otros» ${ }^{44}$. Este rechazo a la eminencia, según Deleuze-junto a la analogía y toda forma de superioridad de una serie sobre otra-, caracteriza el paralelismo spinozista, que, recordemos, es un término que procede de Leibniz ${ }^{45}$, empleado para defender que no hay más superioridad del alma sobre el cuerpo que del atributo pensado sobre el atributo percibido ${ }^{46}$.

La tercera fórmula del paralelismo es una de las que nos acercarán a los vínculos con Diferencia y repetición, así como a la relación desarrollada por Deleuze entre Duns Escoto, Spinoza y Nietzsche. Recuerdo la formulación: «Identidad de ser o unidad ontológica». Esto implica que no solo tienen el mismo orden y la misma conexión, sino que, además, el mismo ser; son las mismas cosas que se distinguen por el atributo del que engloban el concepto. Esta unidad del ser, defenderá Deleuze, es lo que permite a Spinoza rechazar la intervención de un Dios trascendente que relaciona una serie con otra: "Los modos de los atributos son una sola y misma modificación que difiere solamente por el atributo» ${ }^{47}$. De modo que el paralelismo solo se comprende desde un Dios y una causalidad inmanentes, el paralelismo desecha cualquier trascendencia o analogía. Este modelo paralelista de Spinoza nos invita a pensar que, en tanto que todos los atributos son iguales, hay una identidad de conexión entre los modos que difieren por el atributo y, en tanto que los atributos constituyen una sola substancia, los modos que difieren del atributo forman una misma modificación. De manera que "se ve descender la triada de la substancia a los atributos y comunicarse con los modos» ${ }^{48}$. Recapitulemos: la substancia se expresa en los atributos, los atributos son una expresión y la esencia de la esencia es la expresada. La actualización de esta recapitulación a partir de lo explicado en este capítulo sería la siguiente: los atributos se expresan, los modos que dependen

43 Ibidem.

${ }^{44}$ Bernardis, T. Op. cit., p. 29 (la traducción es mía).

45 El concepto "paralelismo» se asigna a la filosofía de Leibniz, cuya doctrina defiende la inseparabilidad del alma y del cuerpo, rechazando cualquier relación de causalidad entre ambos.

46 Deleuze, G. Op. cit., p. 103.

47 Ibidem, p. 102.

48 Ibidem, p. 104 
de los atributos son expresiones y la modificación es expresada. De tal modo que la esencia expresada no se situaba fuera de los atributos, sino que era expresada como la esencia absoluta de la substancia, la misma para todos los atributos, la modificación tampoco existe fuera del modo que la expresa en cada atributo, sino que es expresada como modificación de la substancia, la misma substancia para todos los modos que difieren por el atributo ${ }^{49}$ :

Todo modo es la forma de la modificación en un atributo, toda modificación es el ser en sí de los modos que difieren por el atributo [...]. Los modos que difieren por el atributo expresan una sola y misma modificación, pero esta no existe fuera de los modos que se expresan en los atributos diversos ${ }^{50}$.

Por esto, cuando hablamos del carácter productivo de una esencia divina hemos de concluir que la primera tríada (substancia, esencia atributo) se relaciona con esta última referida a la substancia, la esencia y la modificación ${ }^{51}$. La tríada de la substancia (substancia, atributo, esencia) se prolonga, pues, según Deleuze, en una tríada de modo (atributo, modo, modificación).

\section{III}

El compromiso deleuziano con la univocidad del ser que se expondrá en Diferencia y repetición sigue los pasos de una tradición heterodoxa protagonizada por Duns Escoto, Spinoza y Nietzsche. Lo que trataré de poner de manifiesto en esta sección es la relevancia de estos planteamientos en Diferencia y repetición y la influencia de Spinoza en las consideraciones deleuzianas en torno a la diferencia y la univocidad del ser.

Enfrentarse al problema medieval de saber en qué sentido el ser se dice de los seres comporta, en un principio, dos alternativas. O bien se dice en el mismo sentido, hablamos, por tanto, de univocidad, o bien se dice en muchos sentidos, es decir, la equivocidad. Sin embargo, existe una vía intermedia, que mantiene que ser no es equívoco ni univoco, sino analógico. Esta tradición ortodoxa de la concepción analógica del ser sostiene, tal y como explica Deleuze en su clase del 24 de marzo de 1981, que «... el ser es un concepto análogo, es decir, que se dice de Dios y de las criaturas de manera analógica. El ser infinito se dice de Dios; el ser finito se dice de los hombres $\aleph^{52}$. Esta comprensión del ser implica, en primer lugar, que el ser es un concepto equívoco porque se dice en muchos sentidos de los seres y del ser, pero, también, se entiende que los sentidos se distribuyen de manera jerárquica en relación con los juicios de analogía. Esto pone de manifiesto que Dios es superior a las

\footnotetext{
49 Ibidem, p. 104.

50 Ibidem., p. 106.

51 Cerezo, A. Op. cit., p. 107.

52 Deleuze, G. Diferencia y repetición, Amorrortu, Buenos Aires, 2012, p. 269.
} 
criaturas y, por tanto, es imposible plantear qué es aquello que realmente constituye la individualidad de los seres particulares. En consecuencia, la concepción ligada a la univocidad del ser conformará una tradición heterodoxa, desvinculada del teologismo judeocristiano que caracteriza a la visión analógica. Deleuze reivindicará, en este punto, a Duns Escoto por haber sido el primero en pensar el ser en tanto ser, no como finito o infinito, sino como igual: «Nunca hubo más que una sola ontología, la de Duns Escoto, que da al ser una sola voz, [...] porque supo llevar el ser unívoco al más alto grado de sutileza $\prime^{53}$. Esto implica que, aunque el ser se relacione con las cosas que no poseen el mismo sentido -Dios y las criaturas-, solo hay un único y mismo sentido de la palabra ser. Duns Escoto se adentra en el terreno inexplorado del ser en tanto ser, pero será Spinoza, a juicio de Deleuze, quien lleve las ideas de Escoto a sus últimas consecuencias. La potencialidad de Spinoza radica en que es capaz de manifestar que el ser unívoco no es simplemente pensado en un concepto lógico, sino que es la realidad física en sí misma, es la Naturaleza ${ }^{54}$. Será Nietzsche quien, posteriormente, realice ese ser unívoco, lo dota de potencia propia y lo pone en movimiento en tanto que se mueve al ritmo del eterno retorno. En este sentido, podemos resumir que el ser unívoco se dice en un mismo y único sentido tanto del ser como de los seres y que, a su vez, estos sentidos se distribuyen -ya no de manera analógica- anárquicamente ${ }^{55}$. Deleuze desarrolla una distinción entre sistema jerárquico y anárquico, para referirse a la distinción entre el modelo analógico y el modo unívoco. Trataré a continuación de sintetizar este camino por la univocidad que emprende Deleuze entre Escoto, Spinoza y Nietzsche, con la intención de visibilizar la importancia de las reflexiones de Spinoza y el problema de expresión y la novedad que introduce Deleuze respecto al pensamiento de la univocidad en Diferencia y repetición.

Deleuze plantea en Diferencia y repetición dos cuestiones que debemos tener presentes: «Nunca hubo más que una proposición ontológica: el ser es unívoco» ${ }^{56} \mathrm{y}$ "solo Spinoza ha logrado hacer una ontología" ${ }^{57}$. La primera de ellas se refiere a que la ontología, para Deleuze, se inicia en cuanto se conceptualiza el ser en tanto ser y se afirma el ser unívoco, de ahí que identifique a Duns Escoto como el primero que se aventura a explorar el ser en tanto ser y reivindique a Spinoza como a quien se le atribuye la afirmación del ser unívoco. La segunda sentencia, que acompaña a

53 Ibidem, p. 71.

54 «Entonces hay que imaginar un paso más. Imaginen un paso más, imaginen que alguien encuentra el medio de liberar, de hacer salir de su neutralidad este ser único, este ser en tanto que ser. Es decir que afirma este ser, dice que es lo real; que este ser en tanto que ser es el mismo para todo y para todos; que este ser único, este ser unívoco, no es solamente pensado en un concepto lógico, sino que es la realidad física en sí misma, es la Naturaleza», Deleuze, G. Ibidem, p. 270.

55 "Es una distribución de errancia y aun de "delirio" en la que las cosas se despliegan sobre toda la extensión de un Ser unívoco y no repartido. No es el ser el que distribuye según las exigencias de la representación, sino que todas las cosas se reparten en él en la univocidad de la simple presencia (Uno-Todo)», Deleuze, G. Ibidem, p. 71.

56 Deleuze, G. Ibidem.

57 Ibidem, p. 483. 
la primera -a pesar de que transcurre entre ellas casi la totalidad de la obra-, manifiesta que no existe más que un filósofo, Spinoza, que represente con tanta fuerza el intento por dotar de un estatuto a la univocidad del ser. Tan importante es quien antecede a Spinoza, Duns Escoto, como quien lo sucede, Nietzsche. Esta tríada conforma los tres momentos de la univocidad claves para Deleuze: pensar (Escoto), afirmar (Spinoza) y realizar (Nietzsche) el ser unívoco. Pensar el ser unívoco, entonces, implica pensar el ser en tanto ser. De esto resulta un concepto «neutro» del ser, en tanto que se concibe como indiferente a lo finito y al infinito, a lo universal o singular, en palabras de Francisco Martínez:

Este ser unívoco es indiferente a la actividad y a la pasividad, es neutro, es el mínimo de ser común a lo imposible, lo posible y lo real [...]. Escoto es el primero que ha pensado el ser unívoco para neutralizar la analogía del ser, y lo ha pensado como neutro, en la tradición de Avicena, es decir, como indiferente a lo finito y a lo infinito, a lo singular y a lo universal ${ }^{58}$.

La relación entre este ser neutro, indiferente, y la diferencia es desarrollada por Escoto a través de dos conceptos: la «distinción formal o real» entre los atributos del ser y la «distinción modal» entre las modalidades del ser. La primera, explica Deleuze, es una distinción real dado que se funda en el ser o en la cosa, que se establece entre esencias que pueden dejar subsistir al sujeto al cual se las atribuye ${ }^{59}$. La segunda se refiere a la distinción entre el ser y los atributos y entre las variaciones intensivas de las que son capaces ${ }^{60}$. De modo que, no solo la univocidad del ser se prolonga a lo largo de la organización del ser en tanto que los atributos de Dios son distintos pero unívocos - porque constituyen la esencia del mismo Dios-, sino también las modalidades de Dios (y sus criaturas) que, aunque sean distintas, son unívocas en tanto que constituyen variaciones intensivas del mismo atributo ${ }^{61}$. De manera que, desde la neutralidad, el ser unívoco no implica solo atributos distintos, aunque unívocos a su vez, sino que además los relaciona con factores intensivos (o "grados individuantes») que "varían el modo de ese ser unívoco sin modificar su esencia en tanto ser ${ }^{62}$. De esta manera las distinciones (formales y modales) vinculan al ser con la diferencia.

Siguiendo esta lectura deleuziana de Escoto, es posible concluir que afirmar el ser unívoco, tal como he anticipado, implica hacer del ser unívoco la realidad

58 Martínez, F. Op. cit., pp. 232 y 233.

59 Deleuze, G. Op. cit., p. 77.

${ }^{60}$ Esas variaciones intensivas son, según Deleuze, como las variaciones de lo blanco, son «modalidades individuantes» cuyo infinito y finito constituyen las intensidades singulares, DeLEUzE, G. Ibidem.

${ }^{61}$ «Así, no solo la univocidad del ser (con relación a Dios y a las criaturas) se prolonga en la unidad de los atributos, sino que, bajo la condición de su infinitud, Dios puede poseer esos atributos unívocos formalmente distintos sin perder su unidad», Deleuze, G. Ibidem.

${ }^{62}$ Deleuze, G. Ibidem, p. 78. 
física, es decir, la naturaleza; recordemos la máxima spinozista: «Deus sive, natura» ${ }^{63}$. Por tanto, será Spinoza quien desarrolle una completa organización, ya esbozada en las páginas anteriores y a las que Deleuze se refiere en Spinoza y el problema de la expresión, entre substancia, atributos y modos, partiendo, según Deleuze, de las teorías de las distinciones de Escoto. Veamos cómo lo expresa Deleuze, esta vez, en Diferencia y repetición:

Los atributos se comportan como sentidos cualitativamente diferentes que se relacionan con la substancia como un único y mismo designado y esta substancia se comporta, a su vez, como un sentido ontológicamente uno con respecto a los modos que la expresan, y que son en ella como factores individuantes o grados intrínsecos intensos ${ }^{64}$.

El abismo entre Dios y los seres finitos desaparece con esta afirmación puesto que los atributos comparten formas comunes en tanto que Dios está en las criaturas y viceversa. Spinoza viene a decirnos, según Deleuze, que las mismas formas se dicen de Dios y de los seres finitos, a pesar de no ser iguales (Dios y los seres finitos), las formas en que se dicen de uno y de los otros son las mismas. La jerarquía desaparece, pues, como había explicado en el apartado anterior, se rechaza la eminencia, la idea de que la substancia emana de los atributos y estos de los modos. La univocidad del ser liquida la jerarquía en tanto que una misma substancia es expresada por los atributos conforme a su esencia, mientras que, conforme al grado de potencia de los modos, la substancia (una y misma) es expresada por estos (por los modos). Con Spinoza, dirá Deleuze, el ser unívoco deja de ser neutralizado y se vuelve expresivo, se convierte en una verdadera proposición expresiva afirmativa. Sin embargo, el ser unívoco requiere de una relación entre ser y la diferencia, es decir, se precisa mostrar que el ser solo se dice de la diferencia, pues la substancia spinozista aparece independiente a los modos. Es necesario, expresa Deleuze, que la substancia se diga ella misma de los modos y solo de los modos ${ }^{65}$. Quien desarrolla esto es Nietzsche, que dota al ser unívoco de una potencia de movimiento como eterno retorno. Aquí reside, a juicio de Deleuze, la potencialidad de la propuesta nietzscheana, que, en lugar de mantener la diferencia bajo el dominio de un concepto general, le otorga un concepto propio. ¿De qué manera? A través de una "revolución copernicana» ${ }^{66}$ que parte de la consideración de que el ser se dice del devenir, la identidad de lo diferente y lo uno de lo múltiple ${ }^{67}$. Esto es, que la identidad no es primera, sino una

63 «Con el segundo momento, Spinoza opera un progreso considerable. En lugar de pensar el ser unívoco como neutro o indiferente, hace de él un objeto de afirmación pura. El ser unívoco se confunde con la substancia única, universal e infinita: está anunciado como Deus sive natura. La lucha que emprende Spinoza contra Descartes no es ajena a la que Duns Escoto mantenía con Santo Tomás», Deleuze, G. Ibidem, p. 79.

${ }^{64}$ Deleuze, G. Ibidem, p. 78.

${ }^{65}$ Ibidem, p. 78 y ss.

${ }^{66}$ Ibidem.

67 Ibidem. 
suerte de segundo principio, un principio devenido que gira en torno a lo diferente. El eterno retorno no se refiere al eterno retorno de lo idéntico, pues retornar es la única identidad, identidad de la diferencia, «lo idéntico se dice de lo diferente» ${ }^{68}$. El ser unívoco se relaciona con el eterno retorno en tanto que el ser se dice en uno y mismo sentido de todo aquello que difiere. Deleuze retoma a Klossowski y su interpretación del simulacro para explicar su concepción del eterno retorno nietzscheano. Se trata, en última instancia, de acentuar el aspecto ontológico del simulacro que se genera cuando la apariencia recubre completamente al ser y, por tanto, pierde su subalternidad con respecto al ser:

Pierre Klossowski [...] mantiene que el eterno retorno significa que cada cosa solo existe en la medida en que vuelve, copia de una infinidad de copias que no dejan subsistir ni original ni copia. El eterno retorno califica lo que hace ser (y volver) como simulacro. El simulacro es el verdadero carácter o forma de lo que es tanto que el eterno retorno es la potencia del ser ${ }^{69}$.

El mundo es un conjunto de simulacros, un mundo en continuo devenir, expresado por Nietzsche en su teorización del eterno retorno. No se trata, insisto, de la eterna vuelta de lo mismo, de un devenir protagonizado por la copia de lo mismo. Alejándose de las concepciones platónicas, el eterno retorno es la potencia de afirmar el caos en un mundo dinámico. El eterno retorno hace volver lo mismo solo en tanto que producción de la diferencia y gracias al funcionamiento del simulacro. De modo que el eterno retorno es selectivo, pues no retorna todo, solo retorna aquello que mantiene un orden y anula la diferencia, retornan solo las fuerzas activas, las voluntades de poder afirmativas. El simulacro y el eterno retorno ligado tanto a Klossowski como a Nietzsche y Deleuze permite a ambos autores invertir el platonismo, liberarse de las anteojeras teóricas, como explica Martínez, que mantienen la permanencia en el ámbito de la representación y la sumisión a la tiranía de lo mismo $^{70}$. Pensar el simulacro como la realidad de nuestro mundo implica afirmar el devenir de la diferencia como realidad.

Este pensar el eterno retorno como las diferencias que retornan (y no como la vuelta de lo mismo), así como el carácter selectivo que permite que no retorne lo mismo sino precisamente lo diferente, lo más potente, expresa el ser común de lo extremo, de los grados de potencia en tanto que ya realizados:

El eterno retorno, el volver, expresa el ser común de todas las metamorfosis, la medida y el ser común de todo lo que es extremo, de todos los grados de potencia en tanto realizados. Es el ser-igual de todo lo que es desigual y que ha sabido realizar plenamente su desigualdad ${ }^{71}$.

\footnotetext{
${ }^{68}$ Ibidem.

69 Ibidem, p. 105.

70 Martínez, F. Op. cit., p. 163

${ }^{71}$ Deleuze, G. Op. cit., p. 80.
} 
Esta concepción de la univocidad del ser en el eterno retorno implica el retorno o repetición de todo a lo que se atribuye el ser en tanto que el eterno retorno es, al mismo tiempo, producción de la repetición a partir de la diferencia y selección de la diferencia a partir de la repetición ${ }^{72}$. Esto es, el eterno retorno es selectivo a la vez que productivo haciendo que todo vuelva de la misma manera, aunque se trate de cosas diferentes. Aquí se encuentra la univocidad del ser, en tanto que eterno retorno de distintos modos y configuraciones intensivas. Entonces, a partir de la lectura deleuziana de Nietzsche es posible percibir que el ser se dice de la diferencia. La substancia debe decirse de los modos, en tanto que el ser se dice en un único y mismo sentido de todas las diferencias individuantes, el ser es el mismo para todas las modalidades, aunque ellas mismas no son iguales, se trata de una sola voz del ser «referida a todos sus modos, los más diversos, los más variados, los más diferenciados ${ }^{73}$.

De esta manera la propuesta de Deleuze en Diferencia y repetición no se reduce a hacer que el ser gire en torno a la diferencia y la repetición a partir de las relaciones entre Escoto, Spinoza y Nietzsche, haciendo que el ser unívoco se piense (Escoto), se afirme (Spinoza) y se realice (Nietzsche), sino que, además, se «encarne»: la (onto) génesis del individuo. Spinoza y, por tanto, las reflexiones en torno a su planteamiento desarrolladas en Spinoza y el problema de expresión, no se esfuman en Diferencia y repetición, todo lo contrario, son tomadas por Deleuze y transformadas para tratar de horadar el terreno del ser en cuanto ser para abordar la génesis del individuo. Deleuze manifiesta su compromiso -ya expresado en Spinoza y el problema de la expresión - con la univocidad y la inmanencia spinozista. Que la univocidad mantiene un único y mismo sentido del ser para todos los seres ha sido puesto de manifiesto desde el inicio de este trabajo, pero lo que añadirá Deleuze en Diferencia y repetición será que un ser igual se dice de la diferencia misma. Por su parte, la inmanencia nos hace entender que todo se mueve en un plano fijo, sin referirse a otro superior, sino que todo está implicado en un mismo plano, correlativo a la realidad. Se trata de anunciar «una sola y misma voz para todo lo múltiple» ${ }^{74}$, es decir, de relacionar no solo inmanencia y univocidad, sino entrelazarlas con la intensidad, con los factores individuantes, en tanto que el ser se dice uno y el mismo de las diferencias individuales, solo se dice de ellas (modos). Si en Spinoza la expresión es una categoría ontológica, en Deleuze lo será la diferencia, pues tanto la composición de los modos como la expresión y la diferencia se vuelven individuantes.

La ontología de la diferencia deleuziana y la ontología de la expresión spinozista se encuentran en tanto en la búsqueda de la experiencia real (no posible). Spinoza y el problema de la expresión y Diferencia y repetición se encuentran, se relacionan, la una habita en la otra, en tanto manifestación de un propósito común (entre Deleuze y su interpretación de Spinoza): llevar la expresión del ser unívoco

\footnotetext{
72 Ibidem, p. 61.

73 Ibidem, p. 71.

74 Ibidem, p. 446.
} 
hasta su potencia de individuante y diferencial. La univocidad del ser y la diferencia tienen una conexión profunda, pues la univocidad significa que lo es unívoco es el ser mismo y lo que es equívoco es aquello de lo que se dice.

\section{IV}

A modo de síntesis, el énfasis que pone Deleuze en Spinoza reside en manifestar que no es solo necesario que la substancia se exprese en los atributos, sino que estos se expresen, a su vez, en los modos que designan. Los atributos son, insisto, unívocos en tanto que se dicen de la misma manera de Dios y de las criaturas. A este respecto, el paralelismo spinozista nos permite comprender que los modos de los distintos atributos guardan un mismo orden y conexión: atributos y modos distintos forman parte de un todo. Pero Deleuze añade que esto no implica solo que comparten orden y conexión, sino que, además, tienen el mismo ser. Es esta la univocidad del ser que Deleuze retomará en Diferencia y repetición, la que permite a Spinoza rechazar la existencia de un Dios trascedente y reivindicar la inmanencia. En Diferencia y repetición retomará la teoría ya esbozada en Spinoza y el problema de la expresión en torno a Dios, atributos y modos. Lo que interesa a Deleuze es trazar una genealogía de la univocidad que le lleve a encarnar el ser unívoco. Duns Escoto será el encargado de pensar el ser unívoco; Spinoza, quien lleva el planteamiento de Escoto a sus últimas consecuencias, afirmará el ser unívoco, y, finalmente, Nietzsche es quien realiza el ser unívoco poniéndolo en movimiento y dotándolo de potencia propia. La importancia de Spinoza en esta tríada de autores es la de afirmar el ser unívoco como realidad física, como Naturaleza (Deus sive natura), pues si los atributos comparten formas comunes -dado que Dios está en las criaturas o modos, y estas en Dios- no hay abismo entre Dios y los seres finitos. La substancia no surge de los atributos, ni de los atributos los modos, la univocidad del ser radica en que la misma substancia es expresada por los atributos de acuerdo a su esencia. Finalmente, Nietzsche dota al ser unívoco de una potencia de movimiento como eterno retorno. Eterno retorno no de lo mismo, sino de las diferencias. El ser unívoco se dirá pues en un mismo sentido de aquello que difiere. Todo vuelve de la misma manera, aunque sean cosas diferentes, lo que retorna, lo que se repite es a partir de la diferencia. De modo que las consideraciones desarrolladas por Deleuze en Spinoza y el problema de la expresión relativas a la univocidad del ser y la inmanencia son claves para comprender que el ser igual se dice de la diferencia misma. Lo que tratará de hacer Deleuze en Diferencia y repetición es, precisamente, subrayar el hecho de que se diga de la diferencia misma en tanto que el ser se dice uno y el mismo de las diferencias individuales. Si en Spinoza y el problema de la expresión Deleuze relaciona inmanencia y univocidad, en Diferencia y repetición las entrelaza con la intensidad y los factores individuantes. En última instancia, Spinoza nos acerca a la génesis del sujeto y del individuo que Deleuze aborda, tímidamente, en Diferencia y repetición.

Deleuze y gran parte de sus maestros -Spinoza, especialmente-constituyen los referentes fundamentales de la filosofía materialista, que es retomada por los nuevos materialismos como base teórica. De este modo, la labor pertinente es poner 
en juego el conjunto de consideraciones aquí recogidas con las interpretaciones y visiones que de ello están desarrollando los nuevos materialismos de autoras como Rosi Braidotti, Claire Colebrook o Elisabeth Grosz. Estas filosofías, aunque diversas, tienen como núcleo común a Spinoza y a Deleuze. Parten de un materialismo monista spinozista que sitúa al ser humano en el continuo de la naturaleza, lo que nos invita a desarrollar una mirada holística acerca de nuestra relación con la naturaleza, rechazando ciertas visiones hegemónicas con respecto a una supremacía humana desconectada del resto de seres vivos. Además, retoman tanto de Spinoza como de Deleuze la importancia del cuerpo, proponiendo éticas y políticas encarnadas donde las fuerzas, las energías y los afectos juegan un papel fundamental. Estos planteamientos implican una alteración de perspectivas y la generación nuevas problemáticas alejadas de las dicotomías jerarquizantes. ${ }^{75}$ Estas filosofías reivindican el pensamiento de Spinoza y la lectura deleuziana del mismo, pues, como explica en Spinoza y el problema de la expresión, "no hay más que lo material, estados, afectos y fuerzas que se entrelazan ${ }^{76}$. El sujeto es una expresión momentánea de la infinita posibilidad de la naturaleza. Centrarse en este sujeto implica alejarse de las ficciones comunes que ignoran la multiplicidad. Desde la perplejidad del agitado presente, liberando la mirada hacia las raíces y derivas materialistas de nuestro pensamiento, propongo situarnos en el contexto material del que formamos parte, reivindicando una ética como praxis en la construcción de modos sostenibles de relacionalidad.

ReCiBIDO: octubre de 2018, ACEPTADo: noviembre de 2018

75 Para una presentación más ampliada de los nuevos materialismos, véase CANO, M. «Nuevos materialismos: hacia feminismos no dualistas», Oximora, 7, 2015, pp. 163-180.

${ }^{76}$ Deleuze, G. Spinoza y el problema de la expresión, op. cit., p. 152. 